\title{
Solution of Strain-Softening Surrounding Rock in Deep Tunnel Incorporating 3D Hoek-Brown Failure Criterion and Flow Rule
}

\author{
Jin-feng Zou, Song-qing Zuo, and Yuan Xu \\ School of Civil Engineering, Central South University, No. 22, Shaoshan South Road, Central South University Railway Campus, \\ Changsha, Hunan 410075, China
}

Correspondence should be addressed to Jin-feng Zou; zoujinfeng_csu@163.com

Received 19 March 2016; Accepted 13 June 2016

Academic Editor: John D. Clayton

Copyright (C) 2016 Jin-feng Zou et al. This is an open access article distributed under the Creative Commons Attribution License, which permits unrestricted use, distribution, and reproduction in any medium, provided the original work is properly cited.

In order to investigate the influence of the intermediate principal stress on the stress and displacement of surrounding rock, a novel approach based on 3D Hoek-Brown (H-B) failure criterion was proposed. Taking the strain-softening characteristic of rock mass into account, the potential plastic zone is subdivided into a finite number of concentric annulus and a numerical procedure for calculating the stress and displacement of each annulus was presented. Strains were obtained based on the nonassociated and associated flow rule and 3D plastic potential function. Stresses were achieved by the stress equilibrium equation and generalized Hoek-Brown failure criterion. Using the proposed approach, we can get the solutions of the stress and displacement of the surrounding rock considering the intermediate principal stress. Moreover, the proposed approach was validated with the published results. Compared with the results based on generalized Hoek-Brown failure criterion, it is shown that the plastic radius calculated by $3 \mathrm{D}$ Hoek-Brown failure criterion is smaller than those solved by generalized $\mathrm{H}-\mathrm{B}$ failure criterion, and the influences of dilatancy effect on the results based on the generalized H-B failure criterion are greater than those based on 3D H-B failure criterion. The displacements considering the nonassociated flow rule are smaller than those considering associated flow rules.

\section{Introduction}

A reasonable assessment of plastic failure scope and its deformation is the key to evaluate the safety and stability of tunnel. Analytical and semianalytical solution based on linear and nonlinear failure criteria have been studied by many researchers such as Yu et al. [1, 2], Carranza-Torres [3, 4], and Park and Kim [5]. Yu et al. [1, 2] presented a nonlinear unified strength criterion for rock material, which took the effect of intermediate principal stress into account. Carranza-Torres and Fairhurst [6] were one of the earliest scholars applying the Hoek-Brown failure criterion to the engineering practice. On the basis of this, elastic-brittle-plastic solutions based on the Mohr-Coulomb and Hoek-Brown $(a=0.5)$ failure criteria were proposed by Carranza-Torres [3, 4]. According to the research of Carranza-Torres [3], Sharan $[7,8]$ presented a new solution and calculation method of critical plastic zone using Newton-Raphson method. Due to its feasibility of using computer to obtain numerical solution and simple expression, it has been accepted by most scholars. However, the above results are limited to ignore the influence of the intermediate principal stress on the distribution of stress and displacement of surrounding rock since they are based on generalized Hoek-Brown failure criterion. Hence, there are some deviations with exact solutions because the deep buried tunnel is in the three-dimensional stress state.

Although lots of solutions of surrounding rock were proposed based on the assumption of plane strain problem, the influence of axial stress should not be ignored. The influence of axial stress on the distribution of stress and displacement of surrounding rock was proposed by Reed [9]; he studied the relationship between the axial stress and the major, intermediate, and minor principal stresses. On the basis of Reed [9], Pan and Brown [10] considered the effects of the axial stress and dilation on the convergence and stability of the surrounding rock. In particular, it is pointed out that the case of stress exchange can occur in the calculation. Wang et al. [11] improved Reed's approach and presented an analytical solution of surrounding rock under different axial stresses which is based on Mohr-Coulomb 
failure criterion. Particularly, the stress and displacement of surrounding rock under three different axial stress states were discussed in his paper. The effects of axial stress and in situ stress on stress, displacement, and strain of surrounding rock were studied by Lu et al. [12] and Zhou et al. [13]. Moreover, these approaches can be supplemented and verified mutually. Zou and Su [14] presented an analytical solution of the surrounding rock based on the generalized Hoek-Brown failure criterion and elastic-brittle-plastic model, and this solution is compared with Wang et al. [11] to verify its correctness using the method of parameter transformation. The theoretical solutions for the elastic-brittle-plastic and elastic-plastic rock mass incorporating the out-of-plane stress and seepage force were proposed by Zou et al. [14-18].

Compared with the elastic-plastic model, strain-softening model is closer to failure of rock mass model in engineering practices. Taking into account that rock yield strength does not drop to residual strength instantaneously, strainsoftening process can be regard as a gradual decline in the process of yielding of rock mass. So the strain-softening model can better fit the test curve of rock. For instance, Lee and Pietruszczak [19] proposed a numerical procedure for calculating the stresses and radial displacements around a circular tunnel excavated in a strain-softening Mohr-Coulomb or generalized Hoek-Brown media. In this approach, the potential plastic zone is divided into a finite number of concentric rings and it is assumed that all the strength parameters are linear functions of deviatoric plastic strain. Wang et al. [20] proposed a new closed strain-softening method considering softening process as a series of brittleplastic and plastic flow process and presented a new method to describe the strain-softening process of rock soil mass. Alonso et al. [21] standardized the process of modeling and the problem was transformed into the initial value problem of the Runge-Kutta method. Zou and Li [22] proposed an improved numerical approach to analyze the stability of the strain-softening surrounding rock with the consideration of the hydraulic-mechanical coupling and the variation of elastic strain in the plastic region. Moreover, Zou and He [15] proposed a numerical approach that considers the effect of out-of-plane stress for circular tunnels excavated in strainsoftening rock.

At present, the generalized $\mathrm{H}-\mathrm{B}$ failure criterion is widely used [23-25], but it is difficult to obtain a relatively accurate solution. The majority of scholars have done many researches about three-dimensional failure mechanism including Pan and Hudson [26], Singh et al. [27], Priest [28], Zhang and Zhu [29], and Yang and Long [23, 30]. They proposed different 3D failure mechanisms based on different experimental or theoretical models, respectively. Among these researches, the model proposed by Zhang and Zhu [29], which can be compared with the two-dimensional Hoek-Brown model, is widely recognized.

Although the 3D Hoek-Brown failure criterion has been widely recognized, the theoretical analysis for deep tunnel is still little discussed. The paper focus on the influences of the axial stress on the stress and strain of strain-softening surrounding rock in deep tunnel considering 3D HoekBrown failure criterion. Strains are obtained by the 3D plastic potential function and stresses are given by plane strain method. Moreover, the results are compared with those based on generalized Hoek-Brown failure criterion to find differences between the two methods.

\section{Failure Criterion}

Hoek et al. [31] modified the previous Hoek-Brown failure criterion and proposed the generalized $\mathrm{H}-\mathrm{B}$ failure criterion:

$$
\sigma_{1}-\sigma_{3}=\sigma_{c}\left(m_{i} \frac{\sigma_{3}}{\sigma_{c}}+1\right)^{a},
$$

where $\sigma_{c}$ is the unconfined compressive strength of the rock mass; $\sigma_{1}$ and $\sigma_{3}$ are the major and minor principal stresses, respectively; $m, s$, and $a$ are the $\mathrm{H}-\mathrm{B}$ constants for the rock mass before yielding, which are expressed as follows:

$$
\begin{aligned}
m & =m_{i} \exp \left[\frac{(\mathrm{GSI}-100)}{(28-14 D)}\right], \\
s & =\exp \left[\frac{(\mathrm{GSI}-100)}{(9-3 D)}\right], \\
a & =0.5+\frac{1}{6}\left[\exp \left(-\frac{\mathrm{GSI}}{15}\right)-\exp \left(-\frac{20}{3}\right)\right],
\end{aligned}
$$

where $D$ is a factor that depends on the degree of disturbance to which the rock has been subjected in terms of blast damage and stress relaxation, which varies between 0 and 1 , and GSI is the geological strength index of the rock mass, which varies between 10 and 100 .

The generalized Hoek-Brown failure criterion has been widely used, but the influence of the intermediate principal stress on distribution of stress and strength is neglected. Hence, a 3D Hoek-Brown failure criterion is proposed by Zhang and Zhu [29] on the basis of the generalized HoekBrown and Mogi failure criteria:

$$
\frac{1}{\sigma_{c}^{(1 / a-1)}}\left(\frac{3}{\sqrt{2}} \tau_{\text {oct }}\right)^{1 / a}+\frac{m_{i}}{2}\left(\frac{3}{\sqrt{2}} \tau_{\text {oct }}\right)-m_{i} \sigma_{m, 2}=s \sigma_{c},
$$

where $\tau_{\text {oct }}$ is octahedron deviatoric stress and $\sigma_{m, 2}^{\prime}$ is average effective stress:

$$
\begin{aligned}
\tau_{\text {oct }} & =\frac{1}{3} \sqrt{\left(\sigma_{1}-\sigma_{2}\right)^{2}+\left(\sigma_{2}-\sigma_{3}\right)^{2}+\left(\sigma_{1}-\sigma_{3}\right)^{2}}, \\
\sigma_{m, 2}^{\prime} & =\frac{\sigma_{1}+\sigma_{3}}{2} .
\end{aligned}
$$

The 3D generalized H-B failure criterion not only considers the influence of the intermediate principal stress, but also inherits the merit of the H-B failure criterion. Under the triaxial compression and triaxial tension conditions, the parameters of the $\mathrm{H}-\mathrm{B}$ failure criterion can be directly used for $3 \mathrm{D}$ generalized $\mathrm{H}-\mathrm{B}$ failure criterion.

\section{Computational Model}

As shown in Figure 1, a circular opening with an initial radius $\left(r_{0}\right)$ is subjected to a three-dimensional and uniform in situ 


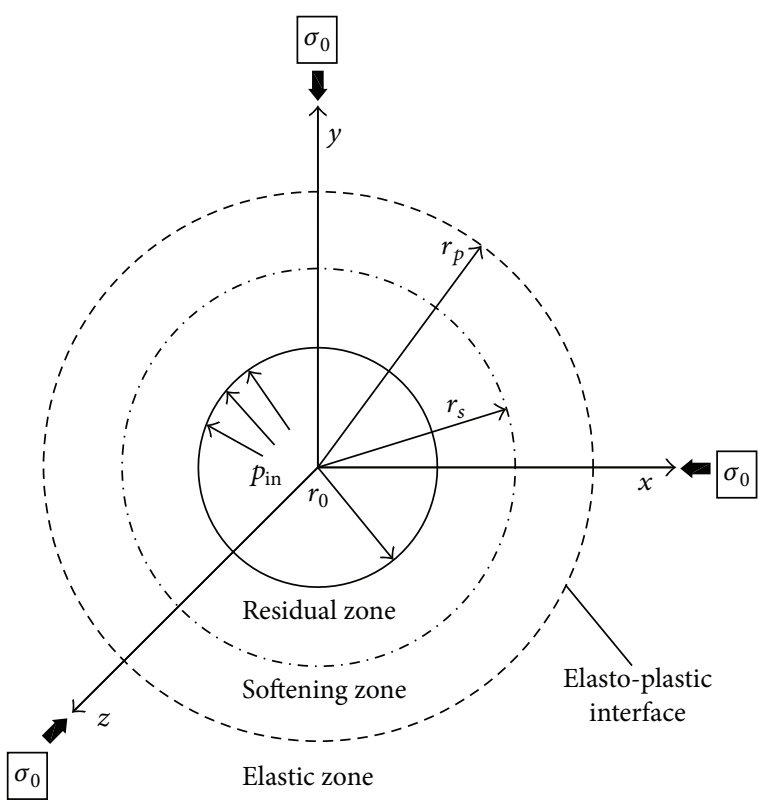

FIGURE 1: Stress state of the surrounding rock.

pressure $\left(\sigma_{0}\right)$ at infinity and an internal support pressure $\left(p_{\text {in }}\right)$ in the tunnel wall. The surrounding rock mass is considered as continuous, homogeneous, isotropic, and initially elastic. Because the axial stress $\left(\sigma_{z}\right)$ along the axis of the deep tunnel is also considered, the analyzed model of surrounding rock can be regarded as spatial axial symmetry model.

During excavation of the deep tunnel, $p_{\text {in }}$ is gradually reduced. When the internal support pressure $\left(p_{\text {in }}\right)$ is less than a critical support pressure, plastic region will appear around the surrounding rock. Because the yielding extent of the surrounding rock is different, the plastic zone of surrounding rock is divided into softening zone and residual zone. The paper considers the surrounding rock to be homogeneous and isotropic material. Therefore, the radial normal strain $\varepsilon_{r}$, the circumferential normal strain $\varepsilon_{\theta}$, and the radial displacement $u_{r}$ can be obtained by small strain assumption as follows:

$$
\begin{aligned}
\varepsilon_{r} & =\frac{\partial u_{r}}{\partial r}, \\
\varepsilon_{\theta} & =\frac{u_{r}}{r} .
\end{aligned}
$$

Outside the plastic zone, the stress and displacement of surrounding rock in elastic zone can be obtained by the solution presented by Reed [9]:

$$
\begin{aligned}
& \sigma_{r}=\sigma_{0}-\left(\sigma_{0}-\sigma_{R}\right)\left(\frac{r_{p}}{r}\right)^{2}, \\
& \sigma_{r}=\sigma_{0}+\left(\sigma_{0}-\sigma_{R}\right)\left(\frac{r_{p}}{r}\right)^{2} .
\end{aligned}
$$

When considering the influence of intermediate principal stress, the axial stress is equal to the in situ stress in deep tunnel as follows:

$$
\begin{aligned}
& \sigma_{z}=\sigma_{0}, \\
& u_{r}=\frac{1}{E}(1+\mu)\left(\sigma_{0}-\sigma_{r_{p}}\right) \frac{r_{p}^{2}}{r} .
\end{aligned}
$$

\section{Strain-Softening Model}

For strain-softening model, the stress-strain curves can be simplified to 3-slope as shown in Figure $2[15,22]$.

The strength and deformation parameters of the strainsoftening rock mass are evaluated based on plastic deformation and are controlled by the deviatoric strain $[19,21]$ :

$$
\gamma^{p}=\varepsilon_{1}^{p}-\varepsilon_{3}^{p},
$$

where $\varepsilon_{1}^{p}$ and $\varepsilon_{3}^{p}$ are the major and minor plastic strains, respectively.

The physical parameters of the surrounding rock mass are described according to the bilinear function of plastic shear strain as follows $[19,21]$ :

$$
\omega\left(\gamma^{p}\right)= \begin{cases}\omega_{p}-\left(\omega_{p}-\omega_{r}\right) \frac{\gamma^{p}}{\gamma_{r}^{p}}, & 0<\gamma^{p}<\gamma_{r}^{p}, \\ \omega_{r}, & \gamma^{p} \geq \gamma_{r}^{p},\end{cases}
$$

where $\omega$ represents a strength parameter, such as $\varphi, c, m, s$, $a, \phi$, and $E ; \gamma_{r}^{p}$ is the critical deviatoric plastic strain from which the residual behavior is first observed and should be identified through experimentation; the subscripts $p$ and $r$ represent the peak and residual values, respectively.

To avoid the influence that the curve of stress and strain in strain-softening stage is nonlinear on theoretical analysis, the strain-softening process can be simplified to a series of brittleplastic processes [20] as shown in Figure 3. The whole plastic zone of the deep tunnel is separated into $n$ rings and the adjacent rings have different parameters. Hence, the actual constitutive model is replaced by piecewise linear $i,(i+1)$ and each segment has different negative slope; it seems like there are $n$ brittle-plastic processes. The greater $n$ is, the more accurate the strain-softening model is.

\section{Solutions in Plastic Zone}

The total plastic region can be divided into $n$ connected annuli which are bounded by annuli of the radii $r_{(i-1)}$ and $r_{(i)}$. The $i$ th annulus is determined by the outer radius $r_{(i-1)}$ and the inner radius $r_{(i)}$ which is adjacent to the elastic region. The parameter values of the outmost ring are equal to the values of innermost elastic region. So the $(n-1)$ iterations of brittle-plastic analysis are conducted on the inner plastic annulus until the residual strength is reached.

The stress equilibrium equation of an element in tunnel wall can be represented by

$$
\frac{\partial \sigma_{r}}{\partial r}+\frac{\sigma_{r}-\sigma_{\theta}}{r}=0
$$

where $\sigma_{r}$ is the radial stress and $\sigma_{\theta}$ is the tangential stress. 


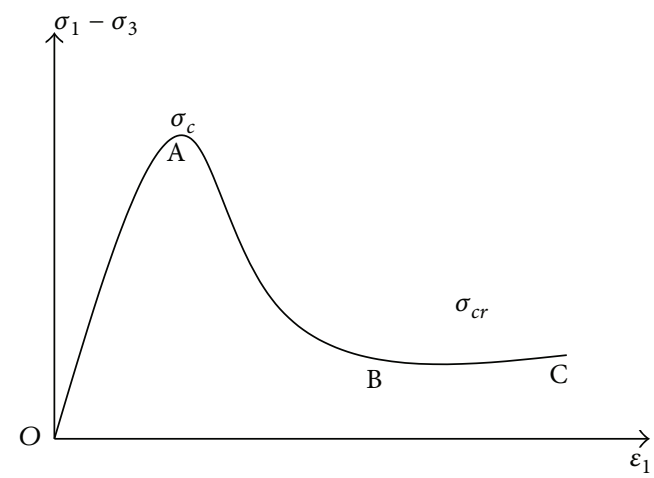

(a) $\left(\sigma_{1}-\sigma_{3}\right)-\varepsilon_{1}$ curves

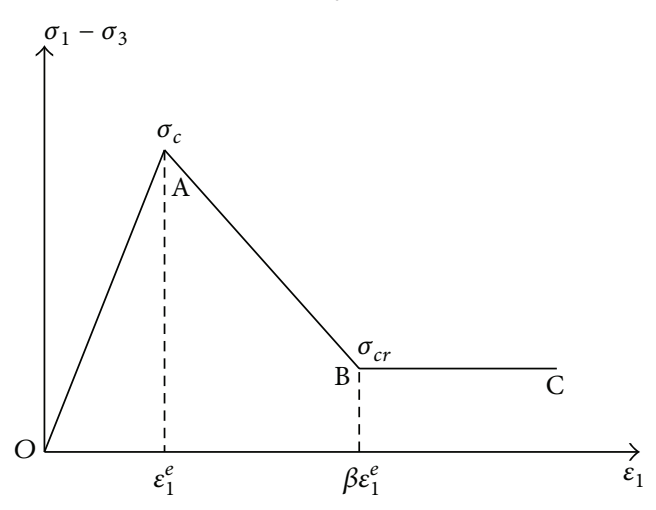

(d) $\left(\sigma_{1}-\sigma_{3}\right)-\varepsilon_{1}$ simplified curves

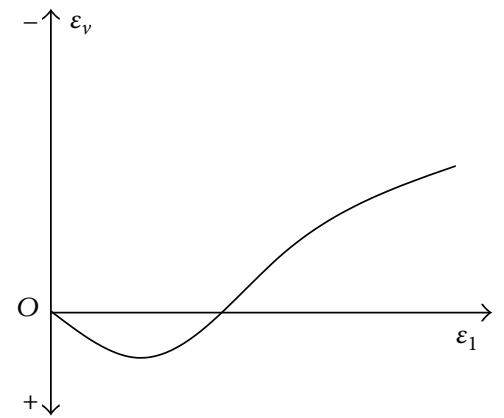

(b) $\varepsilon_{1}-\varepsilon_{v}$ curves

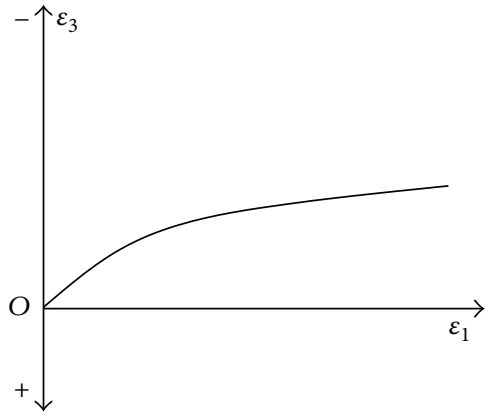

(c) $\varepsilon_{1}-\varepsilon_{3}$ curves
FIGURE 2: Strain-softening material behavior model.

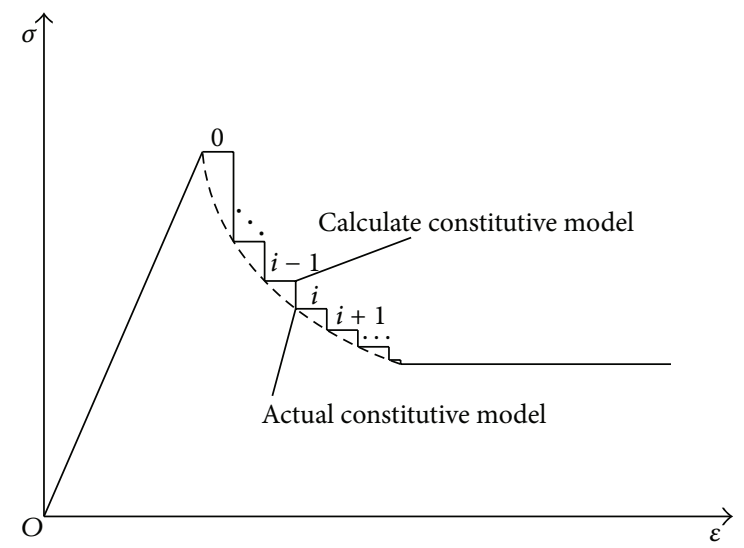

FiguRE 3: Strain-softening model of rock mass.

Based on the plane strain assumption, the axial strain should satisfy

$$
\begin{aligned}
& \varepsilon_{z}=\varepsilon_{z}^{e}+\varepsilon_{z}^{p}=0 \\
& \varepsilon_{z}^{e}=\frac{1}{E}\left[\sigma_{z}-v\left(\sigma_{r}+\sigma_{\theta}\right)-(1-2 v) \sigma_{0}\right] .
\end{aligned}
$$

Hence, the relationship between radial normal stress $\sigma_{r}$, circumferential normal stress $\sigma_{\theta}$, and axial normal stress $\sigma_{z}$ is expressed as

$$
\sigma_{z}=v\left(\sigma_{\theta}+\sigma_{r}\right)-(2 v-1) \sigma_{0}-E \varepsilon_{z}^{p} .
$$

The radial normal stress and the circumferential normal stress at the elastoplastic interface satisfy the failure criterion and can be given by

$$
F\left(\sigma_{1}, \sigma_{3}, \gamma^{p}\right)=\sigma_{1}-\sigma_{3}-H\left(\sigma_{1}, \sigma_{3}, \gamma^{p}\right) .
$$

The radius of the first ring is $r_{(0)}=r_{p}$ which is at the interface between the elastic region and the equivalent plastic zone:

$$
\begin{aligned}
& \rho_{(0)}=\frac{r_{(0)}}{r_{p}}, \\
& r_{(0)}=r_{p} .
\end{aligned}
$$

The stress and strain at the elastoplastic interface can be given by

$$
\left\{\begin{array}{c}
\sigma_{r(0)} \\
\sigma_{\theta(0)} \\
\sigma_{z(0)}
\end{array}\right\}=\left\{\begin{array}{c}
\sigma_{R} \\
2 \sigma_{0}-\sigma_{R} \\
\sigma_{0}
\end{array}\right\},
$$




$$
\left\{\begin{array}{c}
\varepsilon_{r(0)} \\
\varepsilon_{\theta(0)} \\
\varepsilon_{z(0)}
\end{array}\right\}=\frac{1+v}{E}\left\{\begin{array}{c}
\frac{d u}{d r} \\
\frac{u}{r} \\
0
\end{array}\right\}
$$

where

$$
\begin{aligned}
& \varepsilon_{r(0)}=-\frac{1}{2 G}\left\{\sigma_{0}-\sigma_{R}\right\}, \\
& \varepsilon_{\theta(0)}=\frac{1}{2 G}\left\{\sigma_{0}-\sigma_{R}\right\} .
\end{aligned}
$$

The normalized inner radius can be expressed as

$$
\rho_{(i)}=\frac{r_{(i)}}{r_{p}} .
$$

$\sigma_{r}$ on both inner and outer boundaries of the plastic zone are known a priori and $\sigma_{r}$ decreases from $\sigma_{R}$ to $p_{\text {in }}$. The increment of radial normal stress is given by

$$
\Delta \sigma_{r}=\frac{\left(p_{\text {in }}-\sigma_{R}\right)}{n}
$$
by

So the radial normal stress at each ring can be represented

$$
\sigma_{r(i)}=\sigma_{r(i-1)}+\Delta \sigma_{r}
$$

The stress equilibrium equation can be expressed in another way as follows:

$$
\frac{d \sigma_{r}}{d \rho}+\frac{\sigma_{r}-\sigma_{\theta}}{\rho}=0
$$

From above equations, the following expressions can be obtained:

$$
\rho_{(i)} \frac{\Delta \sigma_{r(i)}}{\Delta \rho_{(i)}}=\sigma_{\theta(i)}-\sigma_{r(i)} .
$$

The stress equilibrium differential equation for the $i$ th annulus is derived by using (13) and (20) expressed as (21) and (22):

$$
\begin{aligned}
& \frac{\sigma_{r(i)}-\sigma_{r(i-1)}}{\rho_{(i)}-\rho_{(i-1)}}-\frac{H\left(\sigma_{r(i)}, \gamma^{p}\right)}{\rho_{(i)}}=0, \\
& \rho_{(i)}=\frac{H\left(\sigma_{r(i)}, \gamma^{p}\right)+\Delta \sigma_{r}}{H\left(\sigma_{r(i)}, \gamma^{p}\right)} \rho_{(i-1)} .
\end{aligned}
$$

The radius of each ring is a known quantity and the radial stress of the $i$ th ring can be obtained from (17). So the axial normal stress $\sigma_{z}$ can be given by

$$
\sigma_{z(i)}=v\left(\sigma_{\theta(i)}+\sigma_{r(i)}\right)-(2 v-1) \sigma_{0}-E \varepsilon_{z(i)}^{p} .
$$

Combining (3), (17), and (22), stress at the outer ring can be obtained and the radial stress at the $i$ th ring is calculated by using linear interpolation:

$$
Q_{x}=\frac{Q_{u(i)}-Q_{u(i-1)}}{\rho_{(i)}-\rho_{(i-1)}}\left(\rho_{x}-\rho_{(i-1)}\right)+Q_{u(i)},
$$

where $Q_{x}$ is stress or displacement of rock mass, $Q_{u(i)}$ is stress or displacement of rock mass at $i$ th ring, $Q_{u(i-1)}$ is stress or displacement of rock mass at $(i-1)$ th ring, and $\rho_{x}$ is the distance between center of the tunnel wall and any point of the surrounding rock.

The compatibility equation can be written in the general form as follows:

$$
\frac{d \varepsilon_{\theta}}{d r}+\frac{\varepsilon_{\theta}-\varepsilon_{r}}{r}=0
$$
form:

Equation (26) can be transformed into the following

$$
\frac{d \varepsilon_{\theta}^{p}}{d \rho}+\frac{\varepsilon_{\theta}^{p}-\varepsilon_{r}^{p}}{\rho}=-\frac{d \varepsilon_{\theta}^{e}}{d \rho}-\frac{\varepsilon_{\theta}^{e}-\varepsilon_{r}^{e}}{\rho} .
$$

It can be rewritten as

$$
\frac{d \varepsilon_{\theta}^{p}}{d \rho}+\frac{\varepsilon_{\theta}^{p}-\varepsilon_{r}^{p}}{\rho}=-\frac{d \varepsilon_{\theta}^{e}}{d \rho}-\frac{1+\nu}{E} \frac{H\left(\sigma_{r}, \gamma^{p}\right)}{\rho}
$$

5.1. Associated Flow Rule. According to the geotechnical plastic mechanics, there is an equipotential surface of plastic potential at any point $M$ in stress space. Its mathematical expression is called the plastic potential function, and the plastic potential function can be presented by

$$
g\left(\sigma_{i j}, H_{a}\right)=0
$$

where $H_{a}$ is hardening parameter and $\sigma_{i j}$ is principal stress.

The plastic strain increment $d \varepsilon_{i j}^{p}$ can be obtained by

$$
d \varepsilon_{i j}^{p}=\frac{\partial F}{\partial \sigma_{i j}} d \lambda,
$$

where $d \lambda$ is multiplication operator, $\varepsilon_{i j}^{p}$ is plastic strain, and $\sigma_{i j}$ is principal stress.

It is called the associated flow rule when $F$ and $Q$ are completely the same. And the physical meaning of yield function $F$ is a judgment criterion whether a point of surrounding rock reaches the yield state. And the physical meaning of plastic potential function $Q$ is the relationship between plastic strain increment and loading surface.

While the strains of rock and soil mass satisfy the associated flow rule, its plastic potential function is given by

$$
Q(\sigma)=-\frac{n}{3} I_{1}+\frac{3}{\sigma_{c}} J_{2}+\frac{\sqrt{3}}{2} n \sqrt{J_{2}},
$$

where $n$ is dilation parameter:

$$
\begin{aligned}
& I_{1}=\sigma_{1}+\sigma_{2}+\sigma_{3}, \\
& J_{2}=\frac{1}{6\left[\left(\sigma_{1}-\sigma_{2}\right)^{2}+\left(\sigma_{2}-\sigma_{3}\right)^{2}+\left(\sigma_{3}-\sigma_{1}\right)^{2}\right]} .
\end{aligned}
$$


The differential of three-direction strain is expressed as

$$
\begin{aligned}
d \varepsilon_{\theta}^{p} & =\frac{\partial f}{\partial \sigma_{\theta}} d \lambda=\left[\left(\frac{\sqrt{3}\left(2 \sigma_{\theta}-\sigma_{r}-\sigma_{z}\right)}{12 \sqrt{J_{2}}}-\frac{1}{3}\right) n\right. \\
+ & \left.\frac{1}{\sigma_{c}}\left(2 \sigma_{\theta}-\sigma_{r}-\sigma_{z}\right)\right] d \lambda, \\
d \varepsilon_{z}^{p} & =\frac{\partial f}{\partial \sigma_{z}} d \lambda=\left[\left(\frac{\sqrt{3}\left(2 \sigma_{z}-\sigma_{\theta}-\sigma_{r}\right)}{12 \sqrt{J_{2}}}-\frac{1}{3}\right) n\right. \\
+ & \left.\frac{1}{\sigma_{c}}\left(2 \sigma_{z}-\sigma_{\theta}-\sigma_{r}\right)\right] d \lambda, \\
d \varepsilon_{r}^{p} & =\frac{\partial f}{\partial \sigma_{r}} d \lambda=\left[\left(\frac{\sqrt{3}\left(2 \sigma_{r}-\sigma_{\theta}-\sigma_{z}\right)}{12 \sqrt{J_{2}}}-\frac{1}{3}\right) n\right. \\
& \left.+\frac{1}{\sigma_{c}}\left(2 \sigma_{r}-\sigma_{\theta}-\sigma_{z}\right)\right] d \lambda .
\end{aligned}
$$

If $L_{1}, L_{2}$, and $L_{3}$ are defined as follows

$$
\begin{aligned}
& {\left[\left(\frac{\sqrt{3}\left(2 \sigma_{\theta}-\sigma_{r}-\sigma_{z}\right)}{12 \sqrt{J_{2}}}-\frac{1}{3}\right) n+\frac{1}{\sigma_{c}}\left(2 \sigma_{\theta}-\sigma_{r}-\sigma_{z}\right)\right]} \\
& \quad=L_{1}, \\
& {\left[\left(\frac{\sqrt{3}\left(2 \sigma_{z}-\sigma_{\theta}-\sigma_{r}\right)}{12 \sqrt{J_{2}}}-\frac{1}{3}\right) n+\frac{1}{\sigma_{c}}\left(2 \sigma_{z}-\sigma_{\theta}-\sigma_{r}\right)\right]} \\
& \quad=L_{2}, \\
& {\left[\left(\frac{\sqrt{3}\left(2 \sigma_{r}-\sigma_{\theta}-\sigma_{z}\right)}{12 \sqrt{J_{2}}}-\frac{1}{3}\right) n+\frac{1}{\sigma_{c}}\left(2 \sigma_{r}-\sigma_{\theta}-\sigma_{z}\right)\right]} \\
& \quad=L_{3},
\end{aligned}
$$

then (33) can be simplified to

$$
\begin{aligned}
& d \varepsilon_{1}^{p}=\frac{\partial f}{\partial \sigma_{1}} d \lambda=L_{1} d \lambda, \\
& d \varepsilon_{2}^{p}=\frac{\partial f}{\partial \sigma_{2}} d \lambda=L_{2} d \lambda \\
& d \varepsilon_{3}^{p}=\frac{\partial f}{\partial \sigma_{3}} d \lambda=L_{3} d \lambda .
\end{aligned}
$$

The relationship between radial plastic normal strain $\varepsilon_{r}^{p}$, circumferential plastic normal strain $\varepsilon_{\theta}^{p}$, and axial plastic normal strain $\varepsilon_{z}^{p}$ can be represented by

$$
\begin{gathered}
\frac{\varepsilon_{\theta}^{p}}{L_{1}}=\frac{\varepsilon_{z}^{p}}{L_{2}}=\frac{\varepsilon_{r}^{p}}{L_{3}} \\
\frac{d \varepsilon_{\theta}^{p}}{d \rho}+\frac{\varepsilon_{\theta}^{p}-\varepsilon_{r}^{p}}{\rho}=-\frac{d \varepsilon_{\theta}^{e}}{d \rho}-\frac{1+\nu}{E} \frac{H\left(\sigma_{r}, \gamma^{p}\right)}{\rho} .
\end{gathered}
$$

$$
\text { Combination of (36) and (37) leads to }
$$

$$
\begin{aligned}
\Delta \varepsilon_{\theta}^{p} & =\left(-\frac{d \varepsilon_{\theta(i)}^{e}}{d \rho_{(i)}}-\frac{1+\nu}{E} \frac{H\left(\sigma_{r(i)}, \gamma^{p}\right)}{\rho_{(i)}}\right. \\
& \left.-\frac{\varepsilon_{\theta(i-1)}^{p}\left(1-L_{3(i)} / L_{1(i)}\right)}{\rho_{(i)}}\right)\left(\frac{1}{\Delta \rho_{(i)}}\right. \\
+ & \left.\frac{\left(1-L_{3(i)} / L_{1(i)}\right)}{\rho_{(i)}}\right) .
\end{aligned}
$$

The increment of the radial plastic strain at $i$ th annulus can be obtained by (36):

$$
\begin{aligned}
& \Delta \varepsilon_{r(i)}^{p}=\frac{L_{3(i)}}{L_{1(i)}} \Delta \varepsilon_{\theta}^{p}=\frac{L_{3(i)}}{L_{1(i)}}\left(-\frac{d \varepsilon_{\theta(i)}^{e}}{d \rho_{(i)}}\right. \\
&-\left.\frac{1+\nu}{E} \frac{H\left(\sigma_{r(i)}, \gamma^{p}\right)}{\rho_{(i)}}-\frac{\varepsilon_{\theta(i-1)}^{p}\left(1-L_{3(i)} / L_{1(i)}\right)}{\rho_{(i)}}\right) \\
& \cdot\left(\frac{1}{\Delta \rho_{(i)}}+\frac{\left(1-L_{3(i)} / L_{1(i)}\right)}{\rho_{(i)}}\right) .
\end{aligned}
$$

The displacement at $i$ th annulus can be obtained:

$$
\begin{aligned}
u_{r(i)} & =r_{(i)} \varepsilon_{\theta(i)}=r_{(i)}\left(\varepsilon_{\theta(i)}^{e}+\varepsilon_{\theta(i)}^{p}\right) \\
& =r_{(i)}\left(\varepsilon_{\theta(i)}^{e}+\varepsilon_{\theta(1)}^{p}+\sum_{i=1}^{i} \Delta \varepsilon_{r(i)}^{p}\right) .
\end{aligned}
$$

5.2. Nonassociated Flow Rule. The plastic potential function of the surrounding rock is redefined by Reed [9] by replacing the internal friction angle with the angle of internal friction:

$$
\beta \varepsilon_{1}^{p}+\varepsilon_{3}^{p}=0
$$

where $\beta=(1+\sin \psi) /(1-\sin \psi)$ and $\psi$ is dilation angle.

According to the nonassociated flow rule, we can know

$$
\varepsilon_{2}^{p}=0
$$

So (12) can be rewritten as

$$
\sigma_{z}=v\left(\sigma_{\theta}+\sigma_{r}\right)-(2 v-1) \sigma_{0} .
$$

Therefore, the relationship of strains is no longer determined by the failure criterion considering the nonassociated flow rule but is determined directly by the dilatation coefficient $\beta$ which is defined by the dilation angle $\psi$. Because the intermediate principal strain $\varepsilon_{z}=0$, the relationship between the major and minor principal strains is determined by $L_{1}$ and $L_{3}$ using the associated flow rule. Hence, in order to compare the results calculated by the associated flow rule and nonassociated flow rule, the results of displacement using the nonassociated flow rule can be replaced by using

$$
-\frac{L_{3}}{L_{1}}=\beta=\frac{1+\sin \psi}{1-\sin \psi} \text {. }
$$




\section{Validation}

To validate the correctness of the proposed approach and calculation program, the results of the proposed approach are compared with the results of Sharan [8]. According to different types of the surrounding rock, Sharan provided the strength parameters of indoor test for many groups of rocks. Under different surrounding rock conditions, Sharan [8] calculated the radius of plastic zone and radial displacement of the surrounding rock. The specific parameters are shown in Table 1 and calculation results are shown in Table 2.

If the intermediate stress $\sigma_{z}$ is equal to major principal stress $\sigma_{\theta}$ or minor principal stress $\sigma_{r}$, 3D Hoek-Brown failure criterion can be simplified to two-dimensional Hoek-Brown failure criterion which is used by Sharan.

As shown in Table 2, the results of the paper are in good accordance with Sharan [8] when strain-softening of rock mass is not considered. Under the condition that parameters of surrounding rock are the same, the results show that the greater the stress is, the greater the plastic radius of the surrounding rock is; the larger the internal support pressure is, the smaller the radius of the plastic zone of surrounding rock is. And we found that the results calculated by elasticbrittle-plastic model are larger than those calculated by elastoplastic model. As its strength parameters immediately fall after reaching the peak value, the elastic-brittle-plastic model can be regarded as a special case of strain-softening model.

\section{Numerical Calculation and Discussion}

7.1. Computational Examples. To analyze and compare the proposed approach which considers the intermediate principal stress and the $3 \mathrm{D} \mathrm{H}-\mathrm{B}$ failure criterion with those based on the generalized H-B failure criterion, the following parameters obtained from Sharan's experimental results [8] are adopted: $\sigma_{c}=30 \mathrm{MPa}, s=0.0039, a=0.55, E=5.5 \mathrm{GPa}$, $E_{r}=5.5 \mathrm{GPa}, m=1.7, s_{r}=0.0019, a_{r}=0.6, m_{r}=1.6$, $v=0.25, p_{\text {in }}=5 \mathrm{Mpa}$, and $r_{0}=5 \mathrm{~m}$. The calculation results are shown in Table 3.

Through the comparison results in Table 3, we can find that the plastic zone radius and radial displacement calculated by $3 \mathrm{D}$ H-B failure criterion are smaller than those calculated by generalized $\mathrm{H}-\mathrm{B}$ failure criterion. Thus, it proves that the results may overestimate the plastic zone radii and radial displacement of the surrounding rock without considering intermediate principal stress.

As shown in Table 3, the radial displacement of surrounding rock calculated by associated flow rule is much greater than those calculated by nonassociated flow rule. With different softening parameters, the plastic zone radii calculated by $3 \mathrm{D} \mathrm{H}-\mathrm{B}$ failure criterion are smaller than those calculated by generalized H-B failure criterion. For example, elastoplastic model, strain-softening model $\left(\gamma^{p}=\right.$ 0.006), and elastic-brittle-plastic model would be reduced by $14.57 \%, 14.98 \%$, and $16.00 \%$, respectively. The results of radial displacement using nonassociated flow rule are shown as follows: elastoplastic model, strain-softening model, and elastic-brittle-plastic model $\left(\psi=0^{\circ}\right.$ and $\left.\psi=20^{\circ}\right)$ would

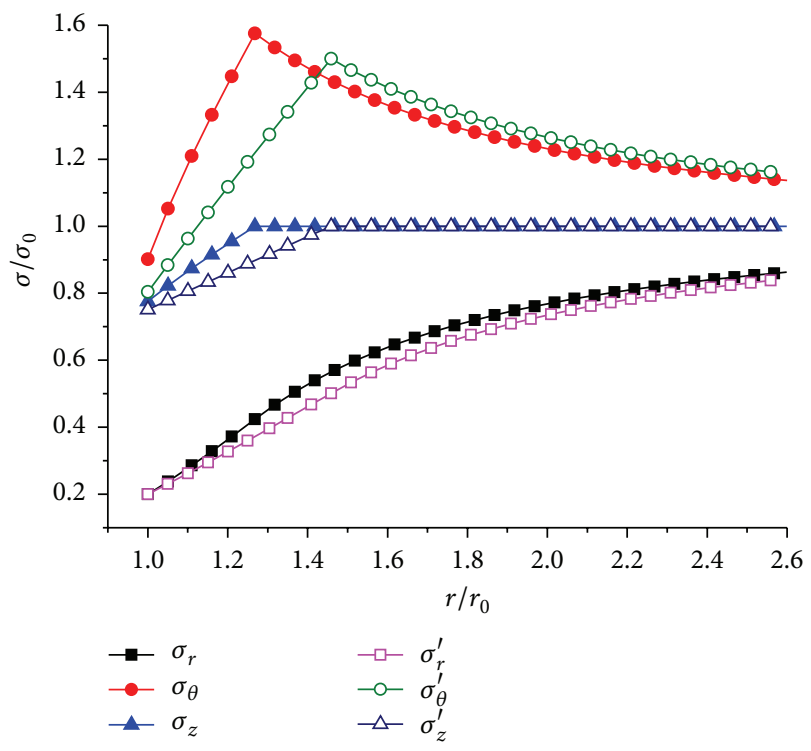

FIGURE 4: Stresses of surrounding rock mass (elastoplastic model).

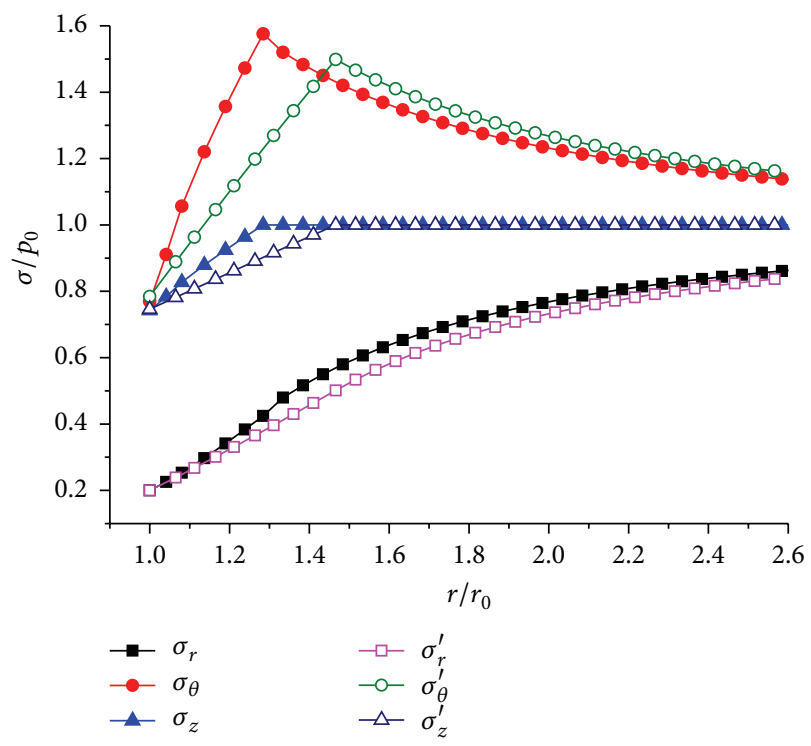

FIGURE 5: Stresses of surrounding rock mass (strain-softening model, $\left.\gamma^{p}=0.04\right)$.

be reduced by $20.85 \%, 34.67 \%, 21.78 \%, 36.29 \%, 21.90 \%$, and $36.53 \%$, respectively. From above results, it can be obtained that the calculated deviations between 3D H-B failure criterion and generalized $\mathrm{H}-\mathrm{B}$ failure criterion increase with the increasing of dilation angle.

At the same time, the radial displacement differences between three-dimensional associated flow rule and nonassociated flow rule considering dilatancy effect are compared. The differences between two calculation approaches are analyzed for predicting the displacement of plastic zone. The results of stress and displacement are shown in Figures 4-11. As shown in Figures $4-7, \sigma_{r}, \sigma_{\theta}, \sigma_{z}$, and $u_{r}$ are calculation results based on $3 \mathrm{D} \mathrm{H}$-B failure criterion; $\sigma_{r}^{\prime}, \sigma_{\theta}^{\prime}, \sigma_{z}^{\prime}$, and $u_{r}^{\prime}$ are calculation results based on generalized $\mathrm{H}-\mathrm{B}$ failure criterion. 
TABLE 1: Calculation parameters [8].

\begin{tabular}{lccccccccccc}
\hline Quality of rock mass & $v$ & $r_{0}(\mathrm{~m})$ & $\sigma_{c}(\mathrm{MPa})$ & $s$ & $s_{r}$ & $a$ & $a_{r}$ & $m_{b}$ & $m_{b r}$ & $E(\mathrm{GPa})$ & $E_{r}(\mathrm{GPa})$ \\
\hline Average & 0.25 & 5 & 80 & 0.0039 & 0 & 0.51 & 0.53 & 2.01 & 0.34 & 9 & 5 \\
Very poor & 0.3 & 5 & 25 & 0.0039 & 0.0019 & 0.55 & 0.6 & 1.7 & 0.85 & 5.7 & 5.7 \\
\hline
\end{tabular}

TABLE 2: Comparisons between the results of this paper and Sharan without considering the strain-softening and intermediate principal stress.

\begin{tabular}{|c|c|c|c|c|c|}
\hline Parameter groups & Elastoplastic model & $\sigma_{0}$ & $p_{\text {in }}$ & $r_{p} / r_{0}($ Sharan $)$ & $r_{p} / r_{0}$ (this paper) \\
\hline 1 & e-p & 40 & 0 & 1.77 & 1.7714 \\
\hline 1 & e-p & 80 & 0 & 2.59 & 2.588 \\
\hline 1 & e-p & 80 & 1 & 2.31 & 2.312 \\
\hline 1 & $e-p$ & 80 & 5 & 1.91 & 1.907 \\
\hline 1 & $e-b-p$ & 40 & 3 & 2.53 & 2.526 \\
\hline 1 & e-b-p & 40 & 5 & 2.03 & 2.030 \\
\hline 1 & $e-b-p$ & 80 & 18 & 2.33 & 2.333 \\
\hline 2 & $e-b-p$ & 15 & 0 & 3.90 & 3.901 \\
\hline 2 & $e-b-p$ & 15 & 3 & 1.51 & 1.510 \\
\hline 2 & $e-b-p$ & 30 & 0 & 7.84 & 7.836 \\
\hline 2 & $e-b-p$ & 30 & 5 & 2.33 & 2.327 \\
\hline
\end{tabular}

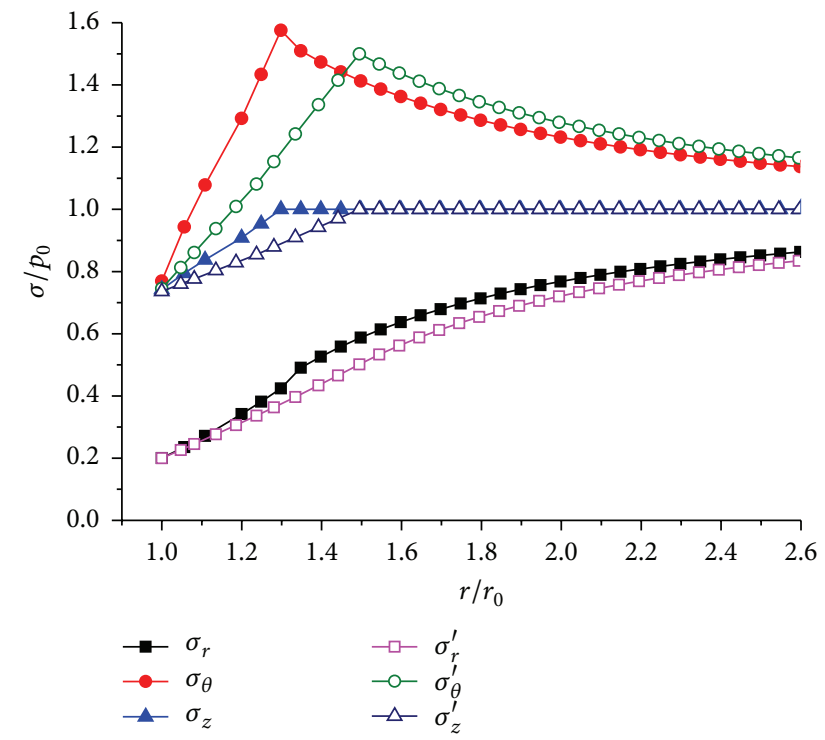

FIGURE 6: Stresses of surrounding rock mass (strain-softening model, $\left.\gamma^{p}=0.006\right)$.

Figures 4-7 show the stress comparisons between the ideal elastoplastic, strain-softening, and elastic-brittle-plastic model based on 3D and generalized Hoek-Brown failure criteria, respectively. When considering the influence of the intermediate principal stress on different failure criterion, the value of plastic radius calculated by the $3 \mathrm{D} \mathrm{H}-\mathrm{B}$ criterion is smaller than those calculated by the generalized $\mathrm{H}-\mathrm{B}$ criterion.

Under the condition that the geotechnical parameters are the same, the influence of dilatation coefficient on generalized $\mathrm{H}-\mathrm{B}$ failure criterion is larger than 3D H-B failure criterion. Particularly as the softening coefficient is the same, the

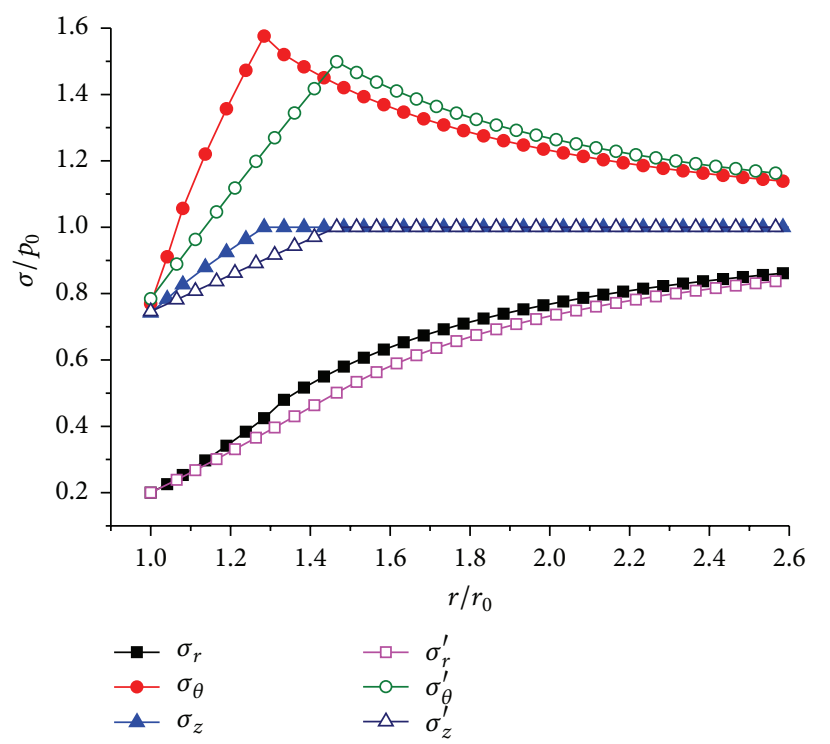

FIGURE 7: Stresses of surrounding rock mass (elastic-brittle-plastic model).

residual radius is smaller than the plastic radius of the surrounding rock if it is calculated by generalized $\mathrm{H}-\mathrm{B}$ failure criterion. For example, if $\gamma^{p}=0.04$, the plastic radius calculated by generalized failure criterion is 1.4660 and the residual radius does not exist. Based on $3 \mathrm{D} \mathrm{H}-\mathrm{B}$ failure criterion, the plastic radius is 1.2841 and the residual radius is 1.0372 . Hence, if the softening coefficient is the same, the plastic radius calculated by different failure criteria is quite different.

The radial displacement comparisons of surrounding rock under different flow rules, softening parameters, and dilation angles are shown in Figures 8-11. Summary results 
TABLE 3: Plastic radius, critical stresses, and displacements of surrounding rock.

\begin{tabular}{|c|c|c|c|c|c|c|c|c|}
\hline & Softening parameters & $r_{p} / r_{0}$ & $r_{s} / r_{0}$ & $\begin{array}{c}\text { Associated flow } \\
\text { rule } \\
u_{r} / r_{0}(\%)\end{array}$ & $\begin{array}{c}\text { Nonassociated } \\
\text { flow rule } \\
\psi=0^{\circ} \\
u_{r} / r_{0}(\%)\end{array}$ & $\begin{array}{c}\text { Nonassociated } \\
\text { flow rule } \\
\psi=7.5^{\circ} \\
u_{r} / r_{0}(\%)\end{array}$ & $\begin{array}{c}\text { Nonassociated } \\
\text { flow rule } \\
\psi=15^{\circ} \\
u_{r} / r_{0}(\%)\end{array}$ & $\begin{array}{c}\text { Nonassociated } \\
\text { flow rule } \\
\psi=20^{\circ} \\
u_{r} / r_{0}(\%)\end{array}$ \\
\hline \multirow{4}{*}{ 2D H-B } & e-p & 1.4591 & 1 & & 0.6793 & 0.7245 & 0.7906 & 0.8534 \\
\hline & $\gamma^{p}=0.04$ & 1.4660 & 1 & & 0.6879 & 0.7373 & 0.8114 & 0.8839 \\
\hline & $\gamma^{p}=0.006$ & 1.4945 & 1.2401 & & 0.7239 & 0.7819 & 0.8676 & 0.9500 \\
\hline & $e-b-p$ & 1.5091 & 1.5091 & & 0.7358 & 0.7947 & 0.8819 & 0.9658 \\
\hline \multirow{4}{*}{ 3D H-B } & e-p & 1.2681 & 1 & 0.7877 & 0.5621 & 0.5815 & 0.6088 & 0.6337 \\
\hline & $\gamma^{p}=0.04$ & 1.2841 & 1.0372 & 0.9599 & 0.5669 & 0.5884 & 0.6194 & 0.6484 \\
\hline & $\gamma^{p}=0.006$ & 1.2980 & 1.2198 & 1.0685 & 0.5944 & 0.6219 & 0.6610 & 0.6970 \\
\hline & $e-b-p$ & 1.3010 & 1.3010 & 1.0873 & 0.6036 & 0.6314 & 0.6710 & 0.7074 \\
\hline
\end{tabular}

TABLE 4: Calculation parameters.

\begin{tabular}{lcccccc}
\hline Rock mass & $s$ & $s_{r}$ & $a$ & $a_{r}$ & $m_{b}$ & $m_{b r}$ \\
\hline 1 & 0.0039 & 0.0039 & 0.55 & 0.6 & 1.7 & 1.7 \\
2 & 0.0039 & 0.0019 & 0.55 & 0.55 & 1.7 & 1.7 \\
3 & 0.0039 & 0.0039 & 0.55 & 0.55 & 1.7 & 1.6 \\
4 & 0.0039 & 0.0039 & 0.55 & 0.55 & 1.7 & 0.85 \\
\hline
\end{tabular}

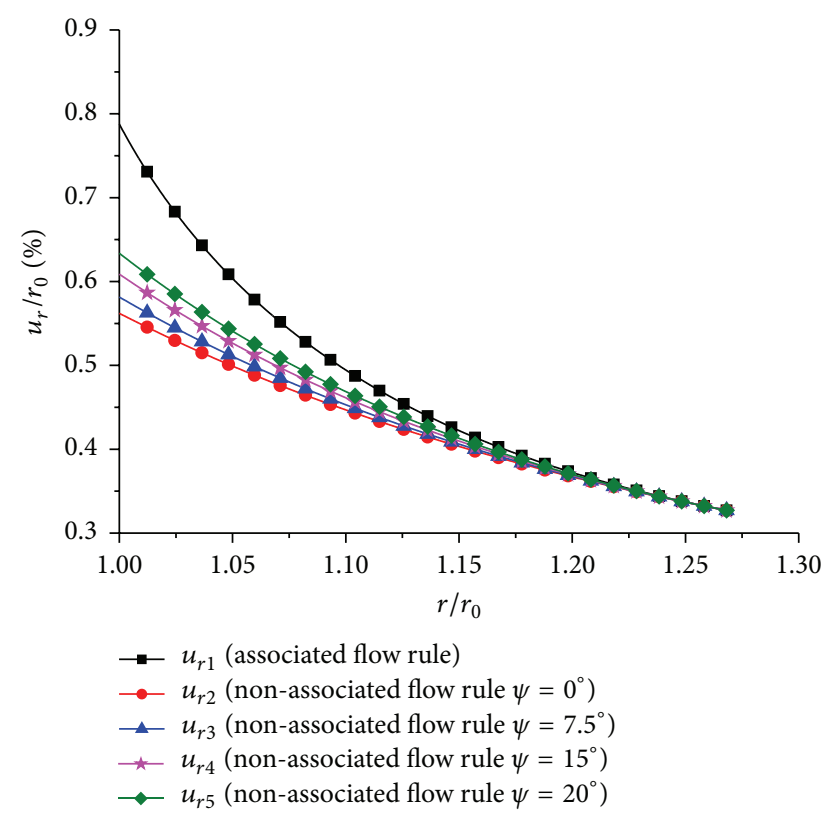

FIGURE 8: Displacements of surrounding rock mass (elastoplastic model).

can be seen from Table 3. The plastic zone radii calculated by associated flow rule and nonassociated flow rule are almost consistent. However, the radial displacement of rock mass increases $10.64 \%$ (e-p model), $11.84 \%\left(\gamma^{p}=0.04\right), 13.91\left(\gamma^{p}=\right.$ 0.006 ), and $14.13 \%$ (e-b-p model) if it adopted associated flow rule. Obviously, with the continuous deteriorations of strength parameters, the result differences between associated flow rule and nonassociated flow rule will increase gradually.

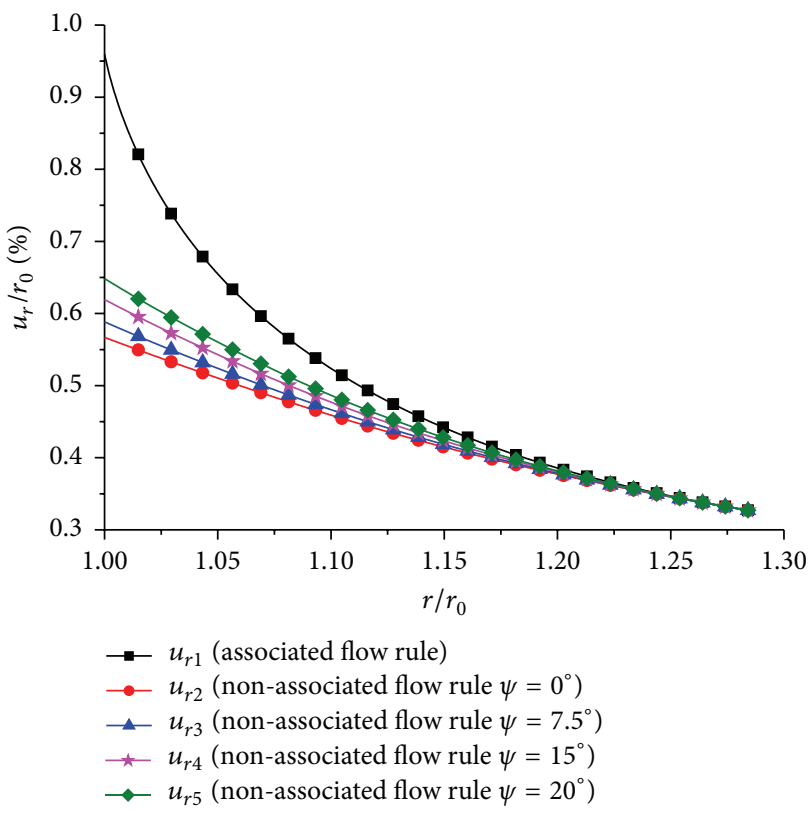

FIGURE 9: Displacements of surrounding rock mass (strainsoftening model, $\left.\gamma^{p}=0.04\right)$.

7.2. Parameter Analysis. In order to analyze the effect of different softening parameters on plastic radius and radial displacement of surrounding rock when considering 3D or generalized $\mathrm{H}-\mathrm{B}$ failure criterion, the following parameters are cited: $\sigma_{c}=30 \mathrm{MPa}, E=5.5 \mathrm{GPa}, v=0.25, p_{\text {in }}=5 \mathrm{Mpa}$, and $r_{0}=5 \mathrm{~m}$. The detailed data are shown in Table 4 .

Elastic-brittle-plastic model (dilation angle is equal to $20^{\circ}$ ) was selected to study the stresses and displacements of surrounding rock as shown in Tables 4 and 5. Compared with the softening process of three parameters, the softening process with only one parameter was conducted. The following conclusions can be drawn as follows: the differences of plastic radius are $1.88 \%$ (2D) and $1.37 \%$ (3D) when only parameter " $a$ " is softening; the differences of radial displacement are $6.28 \%(2 \mathrm{D})$ and $5.77 \%$ (3D) when only parameter " $a$ " is softening; the differences of plastic radius 
TABLE 5: Parameter analyses.

\begin{tabular}{|c|c|c|c|c|c|c|}
\hline H-B & Softening parameters & Groups & $r_{p} / r_{0}$ & $\begin{array}{c}\text { Nonassociated } \\
\text { flow rule } \\
\psi=0^{\circ} \\
u_{r} / r_{0}(\%)\end{array}$ & $\begin{array}{c}\text { Nonassociated } \\
\text { flow rule } \\
\psi=15^{\circ} \\
u_{r} / r_{0}(\%)\end{array}$ & $\begin{array}{c}\text { Nonassociated } \\
\text { flow rule } \\
\psi=20^{\circ} \\
u_{r} / r_{0}(\%)\end{array}$ \\
\hline $2 \mathrm{D}$ & $e-p$ & 1 & 1.4591 & 0.6783 & 0.7897 & 0.8525 \\
\hline $3 \mathrm{D}$ & $e-p$ & & 1.2681 & 0.5621 & 0.6088 & 0.6337 \\
\hline $2 \mathrm{D}$ & $\gamma^{p}=0.006$ & & 1.4771 & 0.7008 & 0.8276 & 0.8996 \\
\hline $3 \mathrm{D}$ & $\gamma^{p}=0.006$ & & 1.2803 & 0.5773 & 0.6331 & 0.6629 \\
\hline $2 \mathrm{D}$ & $e-b-p$ & & 1.4807 & 0.7053 & 0.8327 & 0.9051 \\
\hline $3 \mathrm{D}$ & e-b-p & & 1.2832 & 0.5809 & 0.6367 & 0.6666 \\
\hline $2 \mathrm{D}$ & e-p & 2 & 1.4591 & 0.6783 & 0.7897 & 0.8525 \\
\hline $3 \mathrm{D}$ & $e-p$ & & 1.2681 & 0.5621 & 0.6088 & 0.6337 \\
\hline $2 \mathrm{D}$ & $\gamma^{p}=0.006$ & & 1.4602 & 0.6796 & 0.7919 & 0.8553 \\
\hline $3 \mathrm{D}$ & $\gamma^{p}=0.006$ & & 1.2688 & 0.5629 & 0.6102 & 0.6354 \\
\hline $2 \mathrm{D}$ & $e-b-p$ & & 1.4604 & 0.6800 & 0.7923 & 0.8557 \\
\hline $3 \mathrm{D}$ & e-b-p & & 1.2690 & 0.5632 & 0.6105 & 0.6357 \\
\hline $2 \mathrm{D}$ & $e-p$ & 3 & 1.4591 & 0.6783 & 0.7897 & 0.8525 \\
\hline $3 \mathrm{D}$ & $e-p$ & & 1.2681 & 0.5621 & 0.6088 & 0.6337 \\
\hline $2 \mathrm{D}$ & $\gamma^{p}=0.006$ & & 1.4727 & 0.6953 & 0.8195 & 0.8901 \\
\hline $3 \mathrm{D}$ & $\gamma^{p}=0.006$ & & 1.2775 & 0.5738 & 0.6282 & 0.6574 \\
\hline $2 \mathrm{D}$ & $e-b-p$ & & 1.4777 & 0.7016 & 0.8273 & 0.8988 \\
\hline $3 \mathrm{D}$ & $e-b-p$ & & 1.2814 & 0.5787 & 0.6337 & 0.6632 \\
\hline $2 \mathrm{D}$ & $e-p$ & 4 & 1.4591 & 0.6783 & 0.7897 & 0.8525 \\
\hline $3 \mathrm{D}$ & e-p & & 1.2531 & 0.5877 & 0.6446 & 0.6751 \\
\hline $2 \mathrm{D}$ & $\gamma^{p}=0.006$ & & 1.6778 & 0.9724 & 1.3501 & 1.5894 \\
\hline $3 \mathrm{D}$ & $\gamma^{p}=0.006$ & & 1.4509 & 0.8046 & 1.0370 & 1.1740 \\
\hline $2 \mathrm{D}$ & $e-b-p$ & & 1.7339 & 1.0539 & 1.4379 & 1.6781 \\
\hline $3 \mathrm{D}$ & $e-b-p$ & & 1.4882 & 0.8584 & 1.0797 & 1.2092 \\
\hline
\end{tabular}

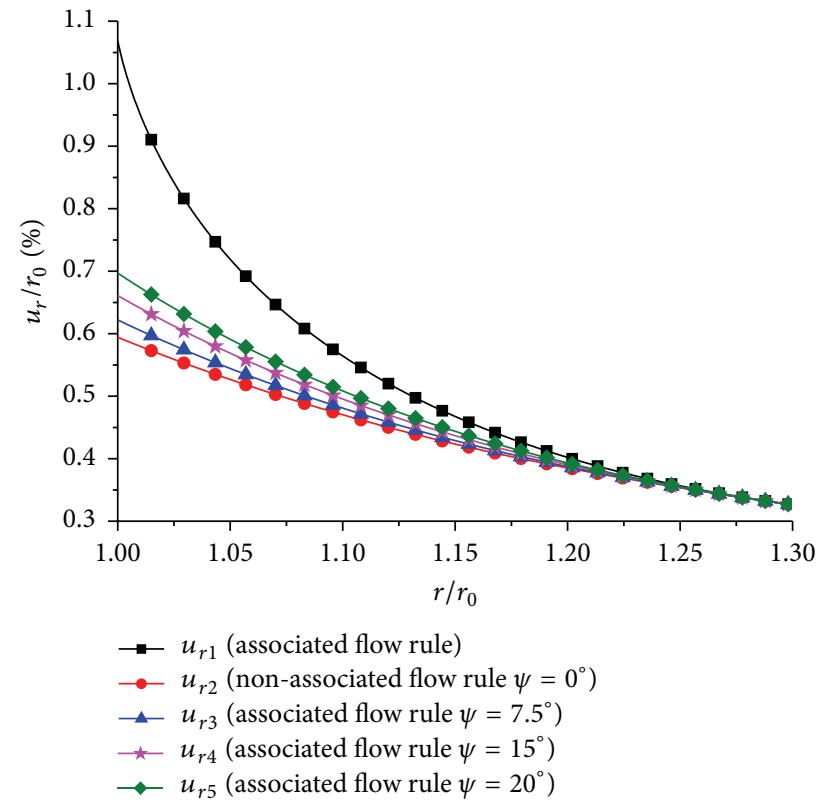

Figure 10: Displacements of surrounding rock mass (strainsoftening model, $\gamma^{p}=0.006$ ).

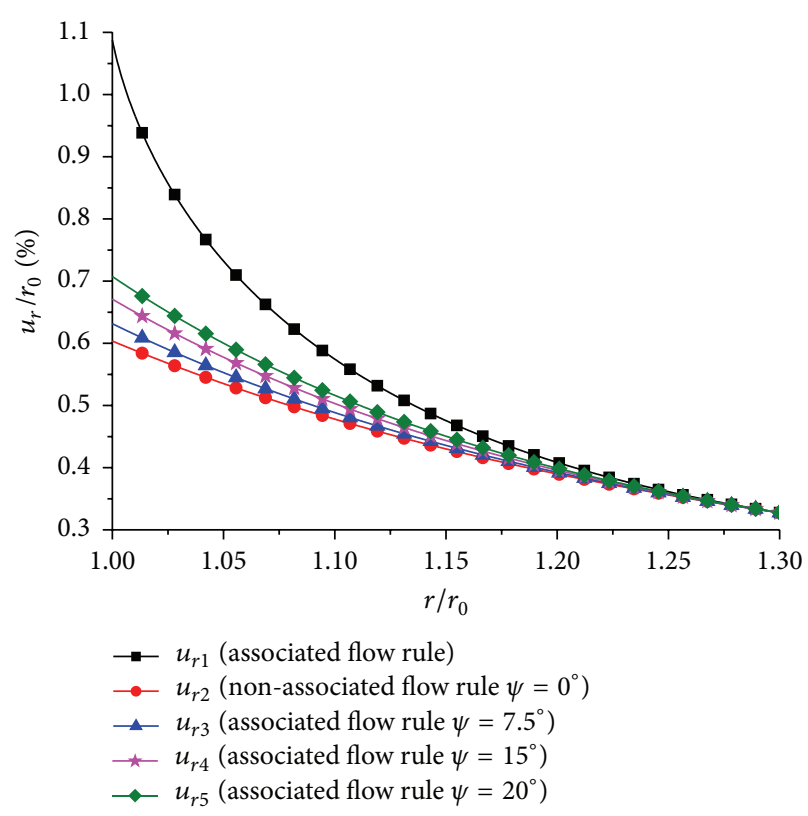

FIGURE 11: Displacements of surrounding rock mass (elastic-brittleplastic model). 
are $3.23 \%(2 \mathrm{D})$ and $2.46 \%(3 \mathrm{D})$ when only parameter " $s$ " is softening; the differences of radial displacement are $11.40 \%$ (2D) and $10.14 \%(3 \mathrm{D})$ when only parameter " $s$ " is softening; the differences of plastic radius are $2.08 \%$ (2D) and $1.51 \%(3 \mathrm{D})$ when only parameter " $m$ " was softening; the differences of radial displacement are $6.93 \%(2 \mathrm{D})$ and $6.25 \%$ (3D) when only parameter " $m$ " is softening.

The above results show that the softening of surrounding rock is commonly decided by many parameters. The order of rock mass parameters affecting the stress and displacements is shown as follows: $s>m>a$.

\section{Conclusions}

(1) Incorporating the 3D Hoek-Brown failure criterion, associated flow rule, nonassociated flow rule, and the strain-softening model, numerical solutions of stress, displacement, and plastic radius were proposed.

(2) Comparison results show that the plastic radius and radial displacement calculated by $3 \mathrm{D}$ Hoek-Brown failure criterion are smaller than those based on generalized Hoek-Brown.

(3) Radial displacement calculated by nonassociated flow rule is smaller than those considering associated flow rule. The influences of dilatancy parameter on the results based on generalized $\mathrm{H}-\mathrm{B}$ failure criterion are larger than those based on 3D H-B failure criterion.

\section{Notations}

a: $\quad$ Parameter of HB failure criterion for peak strength $[-]$

$a_{r}$ : Parameter of HB failure criterion for residual strength $[-]$

$r_{0}$ : Radius of the tunnel opening [L]

$D: \quad$ HB constants for the rock mass [-]

$E$ : Young's modulus of the rock mass $\left[\mathrm{FL}^{-2}\right]$

$m_{b}$ : Parameter of HB failure criterion for peak strength $[-]$

$m_{b r}$ : Parameter of HB failure criterion for residual strength $[-]$

$p_{\text {in }}$ : Critical internal pressure $\left[\mathrm{FL}^{-2}\right]$

$r$ : Radial distance from the center of opening [L]

$r_{p}:$ Plastic radius [L]

$r_{s}:$ Residual radius [L]

$s$ : $\quad$ Parameter of the HB failure criterion for peak strength $[-]$

$s_{r}$ : Parameter of the HB failure criterion for residual strength $[-]$

$u_{r}: \quad$ Radial displacement [L]

$\sigma_{0}:$ Initial in situ stress $\left[\mathrm{FL}^{-2}\right]$

$\sigma_{c}$ : Uniaxial compressive strength of the rock $\left[\mathrm{FL}^{-2}\right]$

$\sigma_{r}:$ Radial normal stress $\left[\mathrm{FL}^{-2}\right]$

$\sigma_{\theta}:$ Circumferential normal stress $\left[\mathrm{FL}^{-2}\right]$ $\sigma_{z}$ : Axial normal stress along the axis of the tunnel $\left[\mathrm{FL}^{-2}\right]$

$\sigma_{1}$ : Major principal stresses $\left[\mathrm{FL}^{-2}\right]$

$\sigma_{2}$ : Middle principal stresses $\left[\mathrm{FL}^{-2}\right]$

$\sigma_{3}$ : Minor principal stresses $\left[\mathrm{FL}^{-2}\right]$

$\sigma_{R}$ : Radial normal stress at the elastoplastic interface $\left[\mathrm{FL}^{-2}\right]$

$\varepsilon_{r}:$ Radial normal strain $[-]$

$\varepsilon_{\theta}$ : Circumferential normal strain $[-]$

$\varepsilon_{z}$ : Axial normal strain $[-]$

$p$ : Plastic parts of normal strain and stress [-]

$e$ : Elastic parts of normal strain and stress [-]

$\psi$ : Dilation angle $[-]$

$\beta$ : Dilation coefficient $[-]$

$\gamma^{p}$ : Softening coefficient of the surrounding rock $[-]$

$v$ : Poisson's ratio of the rock mass $[-]$

$F$ : Yield function $[-]$

Q: Plastic potential function $[-]$.

\section{Competing Interests}

The authors declare that they have no competing interests.

\section{Acknowledgments}

The authors are grateful to the 973 Program (2013CB036004), National Natural Science Foundation of China (no. 51208523).

\section{References}

[1] M. H. Yu, N. L. He, and L. Y. Song, "Twin shear stress theory and its generalization," Scientia Sinica (Sciences in China, English edition) A, vol. 28, no. 11, pp. 1113-1120, 1985.

[2] M.-H. Yu, Y.-W. Zan, J. Zhao, and M. Yoshimine, "A Unified Strength criterion for rock material," International Journal of Rock Mechanics and Mining Sciences, vol. 39, no. 8, pp. 975-989, 2002.

[3] C. Carranza-Torres, "Dimensionless graphical representation of the exact elasto-plastic solution of a circular tunnel in a MohrCoulomb material subject to uniform far-field stresses," Rock Mechanics \& Rock Engineering, vol. 36, no. 3, pp. 237-253, 2003.

[4] C. Carranza-Torres, "Elasto-plastic solution of tunnel problems using the generalized form of the Hoek-Brown failure criterion," International Journal of Rock Mechanics \& Mining Sciences, vol. 41, supplement 1, pp. 629-639, 2004.

[5] K.-H. Park and Y.-J. Kim, "Analytical solution for a circular opening in an elastic-brittle-plastic rock," International Journal of Rock Mechanics and Mining Sciences, vol. 43, no. 4, pp. 616622, 2006.

[6] C. Carranza-Torres and C. Fairhurst, "The elasto-plastic response of underground excavations in rock masses that satisfy the Hoek-Brown failure criterion," International Journal of Rock Mechanics and Mining Sciences, vol. 36, no. 6, pp. 777-809, 1999.

[7] S. K. Sharan, "Elastic-brittle-plastic analysis of circular openings in Hoek-Brown media," International Journal of Rock Mechanics and Mining Sciences, vol. 40, no. 6, pp. 817-824, 2003.

[8] S. K. Sharan, "Analytical solutions for stresses and displacements around a circular opening in a generalized Hoek-Brown 
rock," International Journal of Rock Mechanics and Mining Sciences, vol. 45, no. 1, pp. 78-85, 2008.

[9] M. B. Reed, "The influence of out-of-plane stress on a plane strain problem in rock mechanics," International Journal for Numerical \& Analytical Methods in Geomechanics, vol. 12, no. 2, pp. 173-181, 1988.

[10] X.-D. Pan and E. T. Brown, "Influence of axial stress and dilatancy on rock tunnel stability," Journal of Geotechnical Engineering, vol. 122, no. 2, pp. 139-146, 1996.

[11] S. Wang, Z. Wu, M. Guo, and X. Ge, "Theoretical solutions of a circular tunnel with the influence of axial in situ stress in elastic-brittle-plastic rock," Tunnelling and Underground Space Technology, vol. 30, pp. 155-168, 2012.

[12] A.-Z. Lu, G.-S. Xu, F. Sun, and W.-Q. Sun, "Elasto-plastic analysis of a circular tunnel including the effect of the axial in situ stress," International Journal of Rock Mechanics and Mining Sciences, vol. 47, no. 1, pp. 50-59, 2010.

[13] X.-P. Zhou, H.-Q. Yang, Y.-X. Zhang, and M.-H. Yu, "The effect of the intermediate principal stress on the ultimate bearing capacity of a foundation on rock masses," Computers \& Geotechnics, vol. 36, no. 5, pp. 861-870, 2009.

[14] J. F. Zou and Y. Su, “Theoretical solutions of a circular tunnel with the influence of the out-of-plane stress based on the generalized Hoek-Brown failure criterion," International Journal of Geomechanics (ASCE), vol. 16, no. 3, 2016.

[15] J. F. Zou and Z. He, "Numerical approach for strain-softening rock with axial stress," Proceedings of the Institution of Civil Engineers-Geotechnical Engineering, vol. 169, no. 3, pp. 276290, 2016.

[16] J.-F. Zou, S.-S. Li, Y. Xu, H.-C. Dan, and L.-H. Zhao, “Theoretical solutions for a circular opening in an elastic-brittle-plastic rock mass incorporating the out-of-plane stress and seepage force," KSCE Journal of Civil Engineering, vol. 20, no. 2, pp. 687-701, 2016.

[17] J. F. Zou and S. Q. Zuo, "An approximate solution for the cylindrical cavity expansion problem under the non-axisymmetric displacement boundary condition on hypotenuse," International Journal of Geotechnical Engineering, In press.

[18] J. F. Zou and Z. Q. Xia, "Solutions for displacement and stress in strain-softening surrounding rock incorporating the effects of hydraulic-mechanical coupling and rockbolts effectiveness," Geotechnical \& Geological Engineering, 2016.

[19] Y.-K. Lee and S. Pietruszczak, "A new numerical procedure for elasto-plastic analysis of a circular opening excavated in a strain-softening rock mass," Tunnelling and Underground Space Technology, vol. 23, no. 5, pp. 588-599, 2008.

[20] S. Wang, X. Yin, H. Tang, and X. Ge, "A new approach for analyzing circular tunnel in strain-softening rock masses," International Journal of Rock Mechanics and Mining Sciences, vol. 47, no. 1, pp. 170-178, 2010.

[21] E. Alonso, L. R. Alejano, F. Varas, G. Fdez-Mańin, and C. Carranza-Torres, "Ground response curves for rock masses exhibiting strain-softening behaviour," International Journal for Numerical and Analytical Methods in Geomechanics, vol. 27, no. 13, pp. 1153-1185, 2003.

[22] J. Zou and S. Li, “Theoretical solution for displacement and stress in strain-softening surrounding rock under hydraulicmechanical coupling," Science China Technological Sciences, vol. 58, no. 8, pp. 1401-1413, 2015.

[23] X. Yang and Z. Long, "Seismic and static 3D stability of two-stage rock slope based on Hoek-Brown failure criterion," Canadian Geotechnical Journal, vol. 53, no. 3, pp. 551-558, 2016.
[24] X. L. Yang, J. S. Xu, Y. X. Li, and R. M. Yan, “Collapse mechanism of tunnel roof considering joined influences of nonlinearity and non-associated flow rule," Geomechanics and Engineering, vol. 10, no. 1, pp. 21-35, 2016.

[25] X. L. Yang and R. M. Yan, "Collapse mechanism for deep tunnel subjected to seepage force in layered soils," Geomechanics and Engineering, vol. 8, no. 5, pp. 741-756, 2015.

[26] X. D. Pan and J. A. Hudson, "A simplified three dimensional Hoek-Brown yield criterion," in Proceedings of the ISRM International Symposium, International Society for Rock Mechanics, Madrid, Spain, 1988.

[27] B. Singh, R. K. Goel, V. K. Mehrotra, S. K. Garg, and M. R. Allu, "Effect of intermediate principal stress on strength of anisotropic rock mass," Tunnelling and Underground Space Technology, vol. 13, no. 1, pp. 71-79, 1998.

[28] S. D. Priest, "Determination of shear strength and threedimensional yield strength for the Hoek-Brown criterion," Rock Mechanics and Rock Engineering, vol. 38, no. 4, pp. 299-327, 2005.

[29] L. Zhang and H. Zhu, "Three-dimensional hoek-brown strength criterion for rocks," Journal of Geotechnical and Geoenvironmental Engineering, vol. 133, no. 9, pp. 1128-1135, 2007.

[30] X.-L. Yang and Z.-X. Long, "Roof collapse of shallow tunnels with limit analysis method," Journal of Central South University, vol. 22, no. 5, article no. 2712, pp. 1929-1936, 2015.

[31] E. Hoek, D. Wood, and S. Shah, "A modified Hoek-Brown failure criterion for jointed rock masses," in Proceedings of the International Conference on Eurock, vol. 92, pp. 202-214, September 1992. 


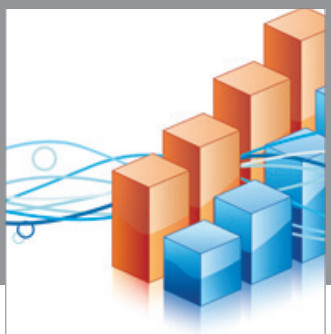

Advances in

Operations Research

vatem alat4

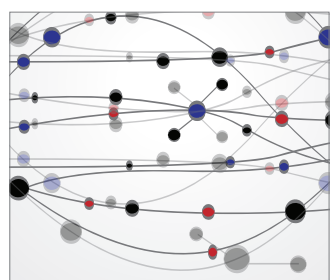

\section{The Scientific} World Journal
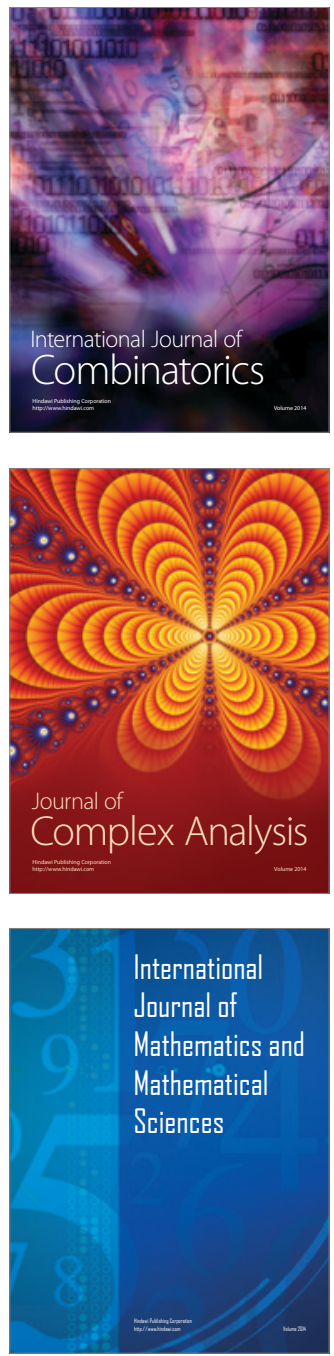
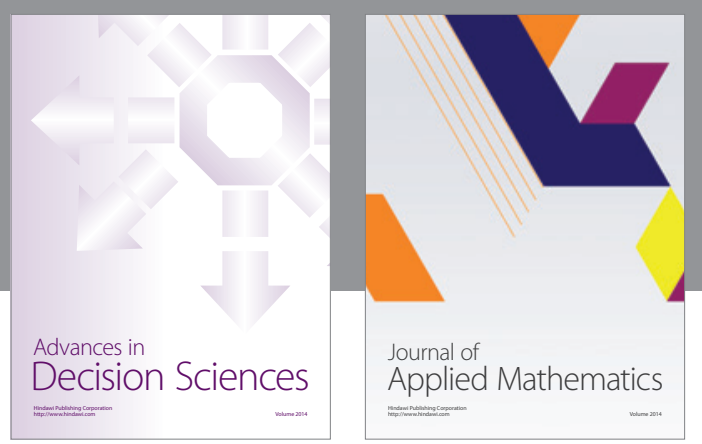

Algebra

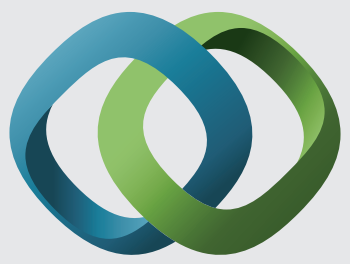

\section{Hindawi}

Submit your manuscripts at

http://www.hindawi.com
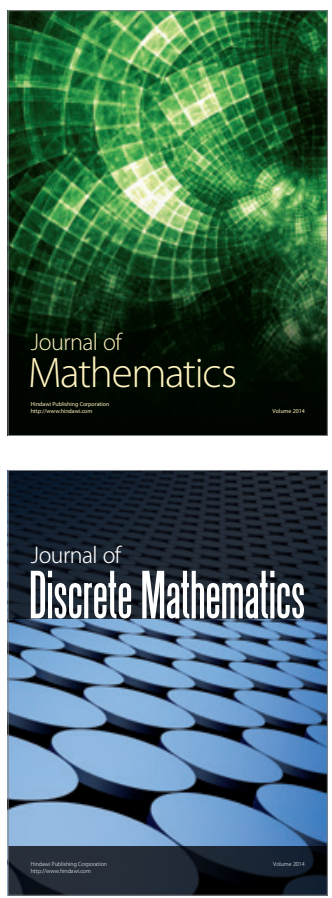

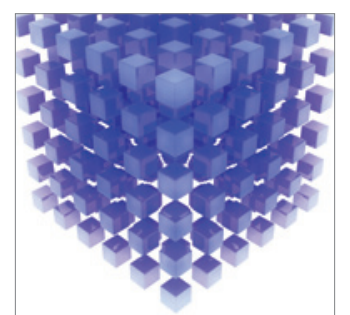

Mathematical Problems in Engineering
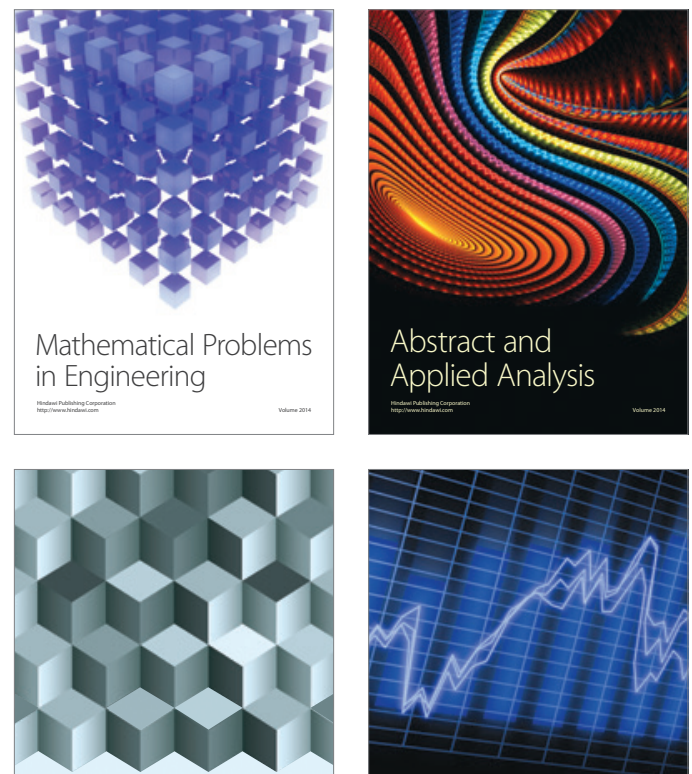

Journal of

Function Spaces

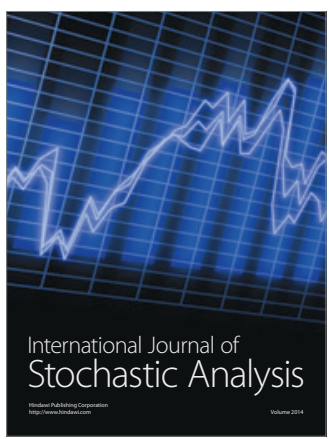

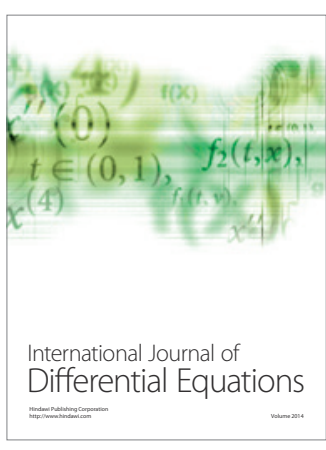
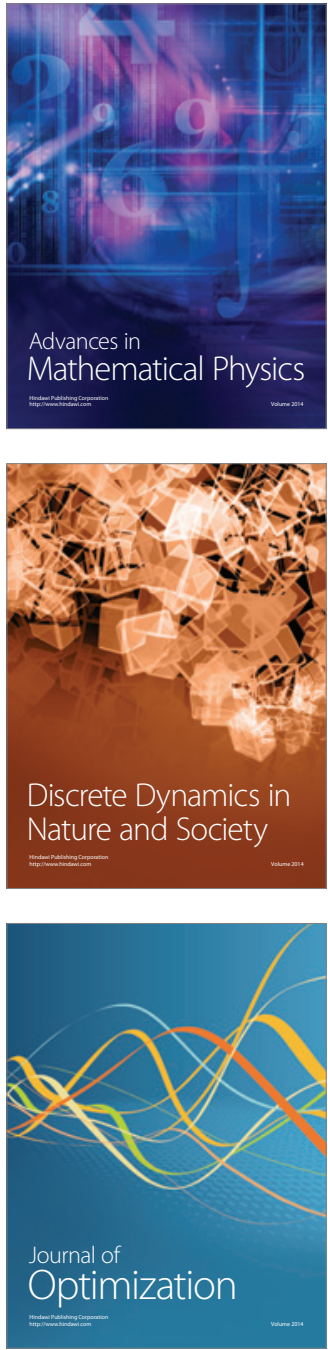